\title{
A Note on an Inherent Difficulty with the Unit Hydrograph Method
}

William James and Robert C. Johanson

This chapter presents previously unpublished work of some time ago. However, the topic remains timely: the re-appraisal of a popular class of simplified, nondeterministic theories regarding the link between rainfall at the ground surface and the resulting runoff. It is shown that linear unit hydrograph theory overlooks the inherent non-linearity in the time dimension of the process. A modified approach, herein called the initial storage theory (IST), is proposed, and tested in the laboratory using a pavement-rainfall-runoff rig.

We deem a theory to be adequate if it permits the accurate calculation of important features of the runoff resulting from a given rainstorm, and conclude that the IST is an improvement over the basic unit hydrograph method. Experiments will be presented in a separate publication; basic methodology is demonstrated herein.

\subsection{Introduction}

This study is described in two out-of-print reports: Johanson, 1967; James and Johanson, 1967. Rainfall reaching the ground surface is generally assumed to split into two parts: part infiltrates into the pervious surface and part runs off to a recipient such as a stream channel. Some of the infiltrated water may also reach

James, W. and R.C. Johanson. 1999. "A Note on an Inherent Difficulty with the Unit Hydrograph Method." Journal of Water Management Modeling R204-01. doi: 10.14796/JWMM.R204-01.

(C) CHI 1999 www.chijournal.org ISSN: 2292-6062 (Formerly in New Applications in Modeling

Urban Water Systems. ISBN: 0-9697422-9-0) 
the channel later by seeping more slowly through the soil. Of course the concept of runoff comprising just two components is an engineering approximation; in reality, many droplets of water experience both surface and sub-surface flow conditions, and changes of state, whilst travelling over and through the ground surface. Overall, the effect of such behavior is that the components of the runoff hydrograph become somewhat merged. This is considered to be generally not serious enough to prevent their being separated at least in theory. In fact we usually consider rainfall to have three components: (i) rain which produces surface runoff, termed effective rainfall; (ii) the second component is that which infiltrates the ground surface and produces sub-surface runoff; and (iii) some rainfall never becomes runoff, due to such effects as the recharge of depression storage and evaporation, and this part of the rain is termed loss. It is difficult to determine the distribution of these three components in time. Usually this is done by making plausible assumptions regarding the time distribution of infiltration. Effective rainfall is then found by subtracting infiltration from the total rainfall hyetograph, which is either observed or assumed.

Here our problem centers on the attenuation and translation effects which transform effective rainfall into a surface runoff hydrograph. These effects are due solely to the characteristics of the process itself and those of the ground surface involved. For example, overland flow is associated with far less attenuation than subsurface flow. In a typical urban application, the hydrograph peak is assumed to be almost entirely derived from the component derived from surface flow.

One popular method for dealing with effective rainfall and runoff is based on the concept of the unit response function (unit hydrograph). In this concept, the surface-runoff process is considered to be a linear system, and capable of relatively straightforward mathematical analysis. Results obtained over many years have shown that the assumption of linearity is justified for some surfaces but much in error for others. Hydrologic systems have been investigated using non-linear systems theory in an attempt to obtain better agreement with observations than is possible with linear systems theory. Meaningful results have been obtained using a laboratory rig. Large errors may arise in working with data from real catchments, because of factors such as inaccurate measurement and the uncertainty involved in separating effective rainfall from total rainfall. Errors may be so large as to nullify the benefits of a complete theory. Methods which may be regarded as compromises between linear and non-linear theory have also been developed. While lacking generality they do extend the range of applicability of the unit hydrograph concept, and allow certain non-linear effects to be dealt with.

We commenced this investigation by building and running experiments on a laboratory pavement-rainfall-runoff rig, and applying linear theory to the results, using effective rainfall and runoff data which was representative of a wide 
variety of conditions. Then we appraised the limitations of the theory, as applied to that ground surface. Later we developed and applied an improved method. Experimental arrangements will be described in a future paper (probably under the authorship of James and Wylie).

\subsection{Background}

This is not the place to describe every development in the understanding of the rainfall-runoff process. In describing progress during the last two generations but one, we have restricted ourselves to contributions that have a direct bearing upon this investigation. Much of the material was obtained from papers by Dooge (1957).

Unit hydrograph concepts were introduced by Sherman (1932). He postulated that, for a given catchment, all runoff hydrographs resulting from rainfall of a given duration have similar time bases, irrespective of the rainfall intensities. Further, he assumed that in such cases the hydrograph shapes are similar, the ordinates being proportional to the intensity of rainfall. Thirdly he assumed that the principle of super-position applies to hydrographs. These three assumptions form the basis of linear theory, of which the unit hydrograph is one case (Clarke, 1945). Since 1932 the unit hydrograph concept has been invested with mathematical elegance by the use of the instantaneous unit hydrograph (IUH). Techniques for deriving the IUH for a catchment from simultaneous records of rainfall and runoff have been developed (Eagleson et al., 1966). Dooge (1959) developed a general theory of the unit hydrograph. He assumed that a catchment consists of many linear reservoirs and channels which together operate on rainfall to produce runoff. One important objective has been the correlation of mathematical IUH parameters with physical parameters of catchments. However the large number of significant catchment parameters makes this a difficult process.

Since it has been found that many catchments are distinctly non-linear in behavior, attention has also been given to the use of non-linear theory. When applied to storms in which the rainfall intensity varies with time, non-linear theory becomes cumbersome (Amorocho and Orlob, 1961). Amorocho (1961) presented a theory in which ascending orders of non-linearity are provided by successive terms in a series-type expression. Singh (1964) proposed a method which was an extension to linear theory. He used an IUH which not only varied with the characteristics of the catchment, but also with the properties of the storm considered. The theory was thus non-linear.

In testing the reliability of any theory, it is essential that accurate data be used. We constructed a laboratory model of a plane impervious surface with a uniform rainfall, and a fast measurement of runoff (many authors describe the general technique, e.g. Amorocho and Harty, 1965; Grace and Eagleson, 1966a). 
Linear theory was applied to the observed hydrographs. Results showed pronounced non-linear behavior, and we concluded that linear theory was inad-equate, at least for our range of experiments. According to our reasoning, runoff processes are inherently non-linear in the time dimension. Rather than resorting to intricate non-linear theory, an approximate method of analysis was developed by the writers to account for the time non-linearity, and tested against the laboratory data. Consideration of the time delay between the commencement of an incremental rainfall and the commencement of the outflow associated with its hydraulic storage, led to our name, Initial Storage Theory.

\subsection{Linear Catchment Theory}

In linear theory the rain-runoff process is regarded as a system with rainfall as its input and runoff as the associated output. Three assumptions concerning such systems underlie linear theory:

1. The system is considered to be a black box with input and output that are functions of time only. Applied to a real catchment, this stipulation excludes the possibility of considering different areal distributions of rainfall intensity - even though such an ideal situation may only be approached in relatively small catchments.

2. Characteristics of the system do not change with time.

3. Any input may be considered to comprise the sum of a number of components, and resolved into them. The postulate that the output resulting from a given input is identical to that which is obtained by superposition of the outputs resulting from all the components of that input, is the core of linear theory.

Rainfall pulse denotes a rainfall of constant intensity and finite duration. Consider a series of hydrographs resulting from rainfall pulses of different intensities but of the same duration TI - the assumption of superposition implies that the ordinates, at similar times, of the various hydrographs are proportional to the causative rainfall intensities. Any of these hydrographs may therefore be reduced to the unit hydrograph, which is the hydrograph that results from unit quantity of rainfall falling uniformly over a period TI.

For a unit hydrograph

$$
\mathrm{i}(\mathrm{t}) \cdot \mathrm{TI}=1
$$

where:

$$
\mathrm{i}(\mathrm{t})=\text { intensity of rainfall at time } \mathrm{t} \text { (constant in this case). }
$$

Therefore

$$
\int_{0}^{\infty} u_{T I}(t) d t=1
$$


where:

$$
\begin{aligned}
\mathrm{u}_{\mathrm{TI}}(\mathrm{t})= & \text { ordinate of unit hydrograph at time } t \text { for rainfall of } \\
& \text { duration TI. }
\end{aligned}
$$

Derivation of the unit hydrograph may be expressed mathematically as:

where:

$$
u_{T I}(t)=q(t) /[T I . i(t)]
$$

$$
\begin{aligned}
& \mathrm{q}(\mathrm{t})=\text { ordinate of hydrograph at time } \mathrm{t} \\
& \mathrm{i}(\mathrm{t})=\text { rainfall intensity associated with } \mathrm{q}(\mathrm{t}) .
\end{aligned}
$$

By transposing Equation 1.3 the hydrograph resulting from rainfall of any intensity may be synthesized if $\mathrm{u}_{\mathrm{TI}}$ is known. Thus far, discussion has been limited to hydrographs resulting from rainfalls of similar duration. Use of the Scurve hydrograph overcomes this limitation. S-curve hydrographs result from rainfall of constant intensity and infinite duration. Such rainfall may be considered a continuous train of pulses. The term $S$-curve derives from the distinctive shape of the function $\mathrm{k}(\mathrm{t})$. Using superposition, a hypothetical S-curve may be constructed by summing hydrograph ordinates associated with each pulse of rain. If all the pulses are identical, the process may be expressed:

$$
k(t)=\sum_{n=0}^{\infty} q(t-n \cdot T I) \quad q(t)=0 \text { for } t \leq 0
$$

where:

$$
\mathrm{k}(\mathrm{t})=\mathrm{S} \text {-curve ordinate at time } \mathrm{t}
$$

By subtracting two identical but lagged S-curves, the hydrograph resulting from a rainfall pulse of arbitrary duration TI may be found:

$$
q(t)=k(t)-k(t-T I)
$$

The S-curve thus provides a method of linking hydrographs which result from rainfall pulses of similar intensity but different durations. Applying proportionality the unit S-curve hydrograph, which results from constant rainfall of unit intensity, may be found:

where:

$$
k_{1}(t)=k(t) / i(t)
$$

$$
\begin{aligned}
k_{1}(t) & =\text { unit S-curve } \\
k(t) & =\text { S-curve for intensity } i(t)
\end{aligned}
$$


Thus it is possible to link the hydrographs resulting from pulses of rainfall of any duration or intensity. It is also possible to synthesize any required hydrograph from any observed or given hydrograph provided that both causative rainfall pulses are known. Unit hydrographs corresponding to rainfall pulses of various durations and corresponding intensities may be derived for a catchment. It is found that the shape of the unit hydrograph approaches a limit as the rainfall pulse duration becomes arbitrarily short. The instantaneous unit hydrograph (IUH) of a catchment is defined as the hydrograph which results when unit quantity of rainfall is instantaneously released uniformly over the ground surface. It is the unit hydrograph corresponding to an infinitesimally short duration of rainfall.

The IUH and the unit S-curve are related. Assume that the unit $S$-curve $k_{1}(t)$ is known. The $S$-curve $k(t)_{2}$ corresponding to a rainfall intensity $i(t)_{2}$ is:

$$
k(t)_{2}=k_{1}(t) \cdot i(t)_{2}
$$

Now define the unit hydrograph $\left(\mathrm{u}_{\mathrm{TT}}\right)_{2}$ as corresponding to a rainfall of intensity $\mathrm{i}(\mathrm{t})_{2}$ and duration $\mathrm{TI}_{2}$ :

$$
\begin{aligned}
\mathrm{i}(\mathrm{t})_{2} \cdot \mathrm{TI}_{2} & =1 \\
\mathrm{k}(\mathrm{t})_{2} & =\mathrm{k}_{1}(\mathrm{t}) / \mathrm{TI}_{2}
\end{aligned}
$$

Using Equation 1.5

$$
\begin{aligned}
\left(\mathrm{u}_{\mathrm{TI}}\right) & =\mathrm{k}(\mathrm{t})_{2}-\mathrm{k}\left(\mathrm{t}-\mathrm{TI}_{2}\right)_{2} \\
& =\left[\mathrm{k}_{1}(\mathrm{t})-\mathrm{k}_{1}\left(\mathrm{t}-\mathrm{TI}_{2}\right)\right] / \mathrm{TI}_{2}
\end{aligned}
$$

Now any value may be assigned to $\mathrm{TI}_{2}$. For an $\mathrm{IUH}$ we let $\mathrm{TI}_{2}$ tend to zero. Then by definition

$$
\left(u_{\mathrm{TI}}\right)_{2} \rightarrow h(t) \text { where } h(t) \text { is the IUH }
$$

Also

$$
\left[\mathrm{k}_{1}(\mathrm{t})-\mathrm{k}_{1}\left(\mathrm{t}-\mathrm{TI}_{2}\right)\right] / \mathrm{TI}_{2} \rightarrow \frac{\mathrm{dk}_{1}(\mathrm{t})}{\mathrm{dt}}
$$

Therefore Equation 1.10 becomes:

$$
h(t)=\frac{d k_{1}(t)}{d t}
$$

Write

$$
h(t)=k_{1}{ }^{\prime}(t)
$$


The IUH is thus the time derivative of the unit S-curve. The unit S-curve may be expressed in terms of the IUH:

$$
\begin{aligned}
& \frac{d k_{1}(t)}{d t}=h(t) \\
& \int_{0}^{t} d k_{1}(t)=\int_{0}^{t} h(t) d t
\end{aligned}
$$

Now for hydrologic systems $\mathrm{k}_{1}(0)=0$

$$
\therefore \mathrm{k}_{1}(\mathrm{t})=\int_{0}^{\mathrm{t}} \mathrm{h}(\tau) \mathrm{d} \tau
$$

The unit S-curve and the IUH are equivalent as far as usefulness is concerned. Here, so far, only hydrographs resulting from rainfall of constant intensity have been considered. The IUH can be used to derive an analytic expression for the runoff hydrograph when the rainfall intensity is variable. Let $\mathrm{i}(\mathrm{t})$ be approximated by a train of short pulses, each of duration $\Delta \tau$. A hydrograph ordinate $q$ at time $t$ comprises elements contributed by those rainfall pulses which occurred in the time interval 0 to $t$. Consider the element $\Delta q(t)$ resulting from the pulse which occurred at time $\tau$ (the quantity of rain in the pulse is $i(\tau) . \Delta \tau)$. Then applying proportionality

$$
\Delta \mathrm{q}(\mathrm{t})=\mathrm{h}(\mathrm{t}-\tau) \mathrm{i}(\tau) \Delta \tau
$$

Summing all such elements $t$

$$
\begin{aligned}
\sum \Delta \mathrm{q}(\mathrm{t}) & =\sum_{\tau=0}^{\mathrm{t}} \mathrm{h}(\mathrm{t}-\tau) \cdot \mathrm{i}(\tau) \Delta \tau \\
\therefore \mathrm{q}(\mathrm{t}) & =\sum_{\tau=0}^{\mathrm{t}} \mathrm{h}(\mathrm{t}-\tau) \cdot \mathrm{i}(\tau) \cdot \Delta \tau
\end{aligned}
$$

Let $\Delta \tau \rightarrow 0$. Then

$$
q(t)=\int_{0}^{t} i(\tau) h(t-\tau) d \tau
$$

This is the well-known convolution or Duhamel's integral, applicable to all linear systems. Equation 1.19 shows that the IUH is the only function involved in effecting the link between rainfall and runoff. In linear theory the IUH therefore completely characterizes the ground surface. It is sometimes termed the kernel of the convolution integral. In practice $h(t)$ and $i(t)$ are sampled data and Equation 1.19 is evaluated numerically. Equation 1.17 may be written: 
where:

$$
\Delta q(n, n+1)=h(n-j+1) \cdot i(j, j+1) \cdot D E L T
$$

$$
\begin{aligned}
\Delta q(n, n+1) & =\text { mean value of } \Delta q \text { in interval } n \text { to }(n+1) \\
i(j, j+1) & =\text { mean value of } i \text { in interval } j \text { to }(j+1) \\
\text { DELT } & =\text { pulse duration. }
\end{aligned}
$$

Let

$$
A(j, j+1)=i(j, j+1) \cdot D E L T
$$

Then

$$
\Delta q(n, n+1)=h(n-j+1) A(j, j+i)
$$

Summing all the elements $\Delta \mathrm{q}$

$$
q(n, n+1)=h(n-j+1) A(j, j+1)
$$

The complete set of these q ordinates may be included by using a matrixvector equation:

$$
\mathrm{q}=\mathrm{A} \cdot \mathrm{h}
$$

Writing some of the elements of this equation:

$$
\begin{aligned}
\mathrm{q}(1,2)= & h(1) \mathrm{A}(1,2) \\
\mathrm{q}(2,3)= & h(1) \mathrm{A}(2,3)+h(2) \mathrm{A}(1,2) \\
\mathrm{q}(3,4)= & h(1) \mathrm{A}(3,4)+h(2) \mathrm{A}(1,2)+h(3) \mathrm{A}(1,2) \\
\ldots \ldots \ldots . . & \\
\mathrm{q}(\mathrm{n}, \mathrm{n}+1)= & h(1) \mathrm{A}(\mathrm{n}, \mathrm{n}+1)+\mathrm{h}(2) \mathrm{A}(\mathrm{n}-1, \mathrm{n})+\ldots \ldots \ldots \ldots \\
& +\mathrm{h}(\mathrm{n}-1) \mathrm{A}(2,3)+h(n) \mathrm{A}(1,2)
\end{aligned}
$$

Equations 1.25 are easy to evaluate. In practice the IUH must be derived from observed rainfall and runoff. When it is required to extract the IUH from observed records, the convolution matrix (Equation 1.24) is inverted:

$$
h=\mathbf{A}^{-1} \cdot q
$$

An easy method of achieving this is as follows, from Equations 1.25:

$$
\begin{aligned}
A(1,2) h(1) & =q(1,2) \\
A(1,2) h(2) & =q(2,3)-h(1) A(2,3) \\
A(1,2) h(3) & =q(3,4)-h(1) A(3,4)-h(2) A(2,3) \\
\ldots \ldots \ldots \ldots & \\
A(1,2) h(j) & =q(j, j+1)-h(1) A(j, j+1)-h(2) A(j-1, j)-\ldots-h(j-1) A(2,3)
\end{aligned}
$$


This is the direct inversion of the convolution matrix. There are other numerical methods which deal with the convolution problem (O'Donnell, 1960). Using linear theory, many workers have been able to derive reasonably accurate IUHs from observed rainfall and runoff. In doing so, it has often been found that an IUH derived for a particular catchment is not unique, but depends on the type of rainfall applied. Attempts were made to explain these observed effects by mathematically modeling in an elementary fashion the basic components of the rainfall-runoff process. Arising from this work, various mathematical forms for the IUH were proposed (Dooge, 1959; Nash, 1957). The possibility of correlating the mathematical parameters of the IUH with certain physical parameters of the catchment and the applied rainfall was studied (Nash, 1960). As a result, theories were developed whereby the variation in shape of an IUH could be calculated. A number of methods embody this approach. Those proposed by Minshall (1960), Singh (1964) and Ishihara (1963) are typical. All these methods are actually extensions to linear theory and accommodate certain non-linear effects. Good results in calculating runoff hydrographs from rainfall hydrographs have been reported in some cases but no generally applicable method has been found.

In our study, we found it impossible to derive accurate IUHs for our laboratory tests. Therefore a new approach capable of adequately explaining the behavior of the model surface was developed and tested.

\subsection{Initial Storage Theory (IST)}

Storage normally builds up on the surface of the ground prior to any appreciable increase in the outflow. Observations made during the course of our test runs, which will be reported in the future, indicated that after the commencement of rainfall a significant time (approximately $25 \mathrm{~s}$ ) elapsed before the rate of runoff become significant. Hydrographs reported by other workers also exhibit this feature (Grace and Eagleson, 1966b; Izzard, 1944; Yu and McNown, 1964). The cause of this observed lag is evident from the governing equation for overland flow (Linsley et al., 1949; Morgali and Linsley, 1965; Yu and McNown, 1964; Izzard, 1946 \& 1944):

where:

$$
\mathrm{qu}=\lambda \mathrm{d}^{\mathrm{m}}
$$

$\mathrm{qu}=$ discharge per unit width

$\mathrm{d}=$ depth of water

$\lambda=$ constant

$\mathrm{m}=$ exponent (for laminar flow $\mathrm{m}$ is approximately 3 , for turbulent approximately 2 ). 
During the early stages of rainfall the depth of water on the surface is small and consequently there is almost no runoff. Rainfall is stored on the surface, retarded by friction at the lower surface and shear stresses induced at the upper water surface by the transverse transfer of momentum of raindrops. Because the exponent $m$ is greater than unity, a stage is reached when the runoff increases rapidly. This accounts for the shape of the observed hydrographs. Surface storage is defined as the accumulated difference between rainfall and runoff. Surface storage also fluctuates. A certain quantity of initial storage is first built up at a rapid, constant rate, whenever rain starts or increases. A second stage is then reached where the rapid increase in the rate of runoff is associated with only a slight increase in the storage, which tends to an equilibrium value. The total storage may thus be regarded as consisting of two components, both of which are released when the rainfall ceases, or decreases. These two components suggests the concept of two corresponding components of rainfall and runoff:

1. Rainfall occurring during the initial storage period TS, builds up the total initial storage $S$ while little runoff takes place. After the cessation of rainfall this storage is released, forming a portion y of the total hydrograph recession.

2. This component incorporates all the rainfall and runoff which is not associated with the first component. The rainfall involved is therefore that which occurs between times TS and TI. The runoff component $\mathrm{x}$ consists of all the runoff which takes place between times TS and TI, plus a portion of the recession flow.

Three assumptions are made concerning the behavior of these two components:

1. Initial Storage $\mathrm{S}$ does not depend on the absolute rainfall intensity, or the shape of the rainfall hyetograph, and is considered to be constant for similar rain intensity increments.

2. The second component of the system behaves linearly and thus may be represented by an S-curve.

3. Depletion of Initial Storage, curve $y(t)$, commences at time TI and represents the first component of runoff. Its shape does not vary for a given runoff surface.

Summarizing the above, hydrographs from any given ground surface may be reduced to (or calculated from) the following invariant parameters and functions:

1. Initial Storage S.

2. An S-curve for the linear component.

3. Initial storage depletion function $y(t)$.

IST differs from linear theory in that three parameters are used to characterize a ground surface instead of a single IUH. If the initial storage on a ground surface is zero, then the method reduces to linear analysis; linear theory is thus a special case of IST. A hydrograph may be resolved into the three parameters as follows. 


\subsubsection{Estimation of the Three Ground Surface Parameters}

Firstly the IST is applied to hydrographs in which the rainfall intensity does not vary. By imposing this restriction, the method is considerably simplified. Later in this chapter we extend the method to rainfall hyetographs of arbitrary shape. Figure 1.1 shows the analysis of a typical rainfall and runoff.
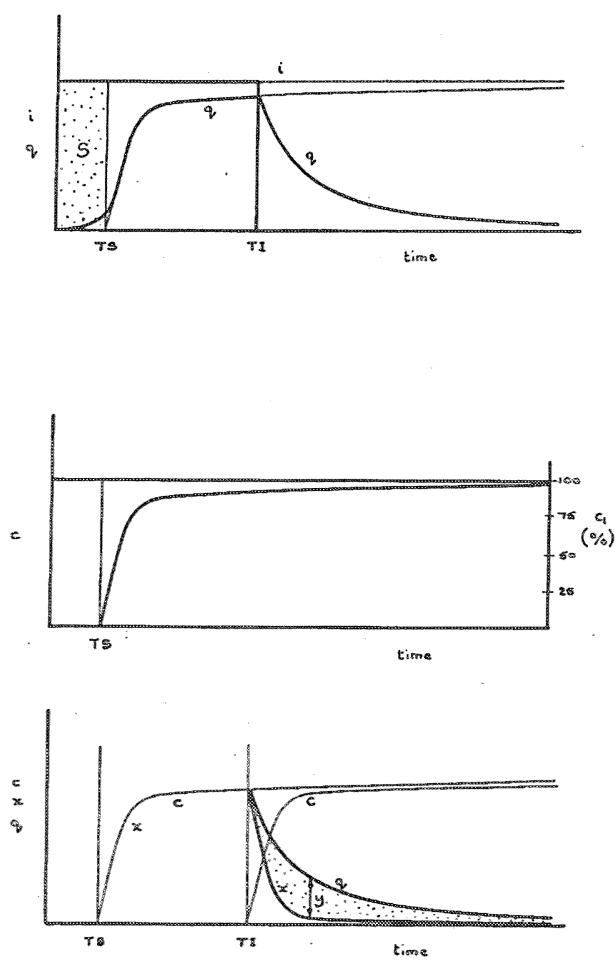

Figure 1.1 Schematic of three components of the initial storage method (initial storage, $\mathrm{S}$, linear component, $\mathrm{c}$, and depletion of initial storage, $\mathrm{y}$ ).

Initial Storage: As there is always a small amount of runoff during the initial storage period, it is impossible to determine TS directly from a hydrograph. The steep accession portion of the hydrograph is extended straight backwards to give TS the point of intersection with the time axis. The initial storage is:

$$
S=T S . i
$$

Linear Component: Both the rainfall hyetograph and runoff hydrograph of the linear component commence at time TS. The curve $\mathrm{x}$ follows the modified total runoff hydrograph until time TI. An S-curve for this linear component is obtained 
by producing the runoff hydrograph beyond time $\mathrm{TI}$ to meet the rainfall intensity line asymptotically. The curve so formed does not resemble the letter $S$. To distinguish it from the normal S-curve, it will hereinafter be referred to as a $C$ curve. A unit $\mathrm{C}$-curve, derived in a similar fashion to a unit $\mathrm{S}$-curve, is used to characterize the linear component of the system, i.e:

where:

$$
c_{1}(t)=c(t) / i
$$

$$
\begin{aligned}
c_{1}(t)= & \text { unit } C \text {-curve ordinate at time } t \text {. The origin for both } \\
& \text { functions is located at TS. }
\end{aligned}
$$

Depletion of Initial Storage: The initial storage depletion function is the difference between the total hydrograph recession curve, and its linear component. The linear component is found from:

$$
x(t)=c(t)-c(t-T I+T S) \quad(t \geq T I)
$$

The origin of $\mathrm{x}$ is at TS. The function $\mathrm{y}$ always commences at time TI. Accordingly, its origin is fixed at that point. Therefore:

$$
y(t-T I)=q(t)-x(t-T S) \quad(t \geq T I)
$$

Equation 1.32 permits the initial storage depletion function to be evaluated.

\subsubsection{Verification}

As described elsewhere, we tested the IST by deriving the ground surface parameters from a wide range of observed laboratory hydrographs. The validity of the assumptions was then judged by the degree of consistency shown in the parameters. We previously used the same method to test linear theory, but it failed because it was not possible to derive consistent IUHs. Failure does not arise with the IST, however, because it is always possible to derive the three surface parameters. A series of eighteen tests, covering nine different rainfall conditions was run on the laboratory rig (each test was duplicated). The series of tests covered three different rainfall intensities, and it was possible to draw three different $\mathrm{C}$-curves and to derive three values of $\mathrm{S}$, each of which was based on the results of six tests. Mean values of TS were measured and the initial storage $\mathrm{S}$ calculated in each case. It was evident that neither TS nor $\mathrm{S}$ were constant, but the error involved in assuming $S$ constant throughout the range of the apparatus was only $\pm 10 \%$ about the mean value. The assumption was deemed to be an adequate approximation. 
Using the revised values of TS, three C-curves were drawn, each corresponding to a different rainfall intensity. The necessary visual extrapolation of the hydrographs was accomplished with accuracy because in many tests the rate of runoff approached the equilibrium value. The corresponding unit $\mathrm{C}$-curves were derived and the concept of an approximately invariant unit $\mathrm{C}$-curve found to be tenable. Whereas the parameters $\mathrm{S}$ and $\mathrm{c}_{1}(\mathrm{t})$ are derived from a $\mathrm{C}$-curve only, use is also made of the hydrograph recession in calculating $y(t)$. Nine recession curves were available, each of which was the mean of two observed hydrographs. Nine $y(t)$ curves were therefore derived. The $y(t)$ curves were also very consistent. For constructing a runoff hydrograph, the procedure is virtually the reverse of that above.

Strictly speaking, the assumption that the parameters of a given surface do not change with the rainfall conditions was found to be incorrect. Results obtained did, however, indicate that the ordinates of calculated runoff hydrographs were accurate to within $10 \%$ of the peak value, except in the steep zones of the accession and recession curves.

\subsection{Runoff Calculation}

The ultimate test of any theory of surface runoff is the degree of success with which the calculation of runoff hydrographs can be achieved. Two worked examples are presented here, wherein we assume that ground surface parameters may be determined from prior knowledge (observed hyetographs and hydrographs), and the problem is to calculate new runoff hydrographs, which would result from given rainfalls. The procedure is virtually the reverse of that which we used for analysis. The intensity $i$ and duration TI of the rainfall giving rise to the calculated hydrograph must be known. Then:

where:

$$
\mathrm{TS}=\mathrm{S}^{*} / \mathrm{i}
$$

$$
\begin{aligned}
\mathrm{TS} & =\text { initial storage period of the calculated hydrograph } \\
\mathrm{S}^{*} & =\text { mean value of initial storage. }
\end{aligned}
$$

The required $\mathrm{C}$-curve is found from

$$
c(t)=c_{1}(t) \cdot i
$$

The duration of rainfall for the linear component is (TI - TS). The runoff hydrograph for that component is thus:

$$
x(t)=c(t)-c(t-T I+T S)
$$


The origin of $x$ is at TS. Allowing for the different origins involved, the calculated hydrograph of total outflow is

$$
q(t)=x(t-T S)+y(t-T I)
$$

Table 1.1 Tests used for calculation.

\begin{tabular}{clrrr}
\hline Example & & Test \# & $\mathrm{i}(\mathrm{mm} / \mathrm{hr})$ & TI (secs) \\
\hline \multirow{2}{*}{1} & Given & 131 & 51 & 60 \\
& Calculated & 119 & 128 & 120 \\
\cline { 2 - 5 } 2 & Given & 133 & 51 & 60 \\
& & 120 & 91 & 120 \\
& \multirow{2}{*}{ Calculated } & 118 & 128 & 60 \\
\hline
\end{tabular}

Results are plotted in Figures 1.2 and 1.3 respectively. In both cases the calculated curves are similar to those which were observed. In Example 2 the results were particularly good.

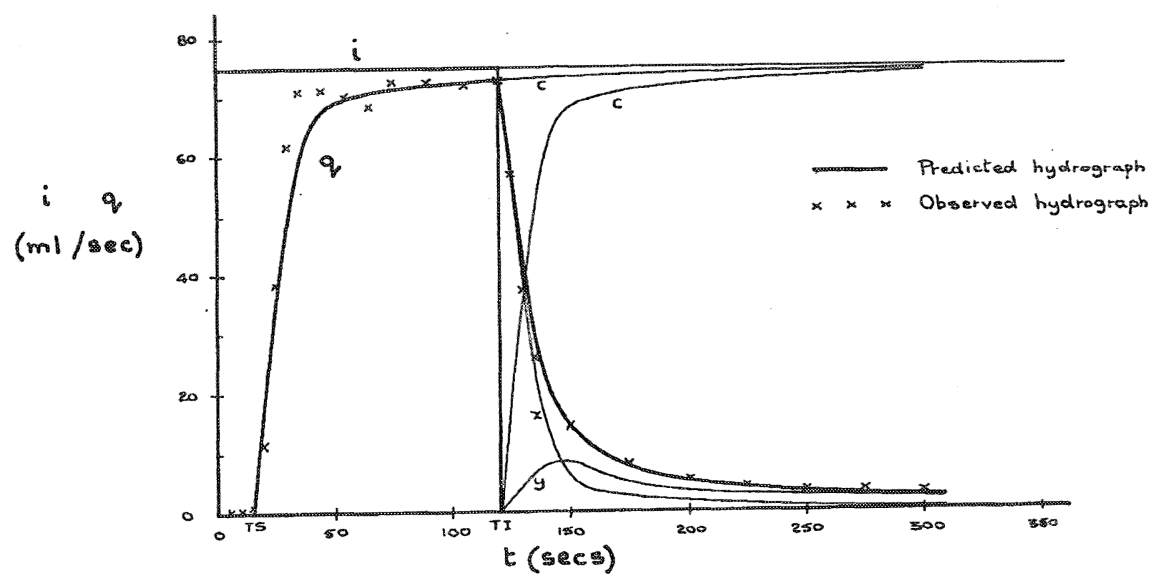

Figure 1.2 Results for a long-duration rain. (Shows derived TS, $\mathrm{c}$ and $\mathrm{y}$ ). 


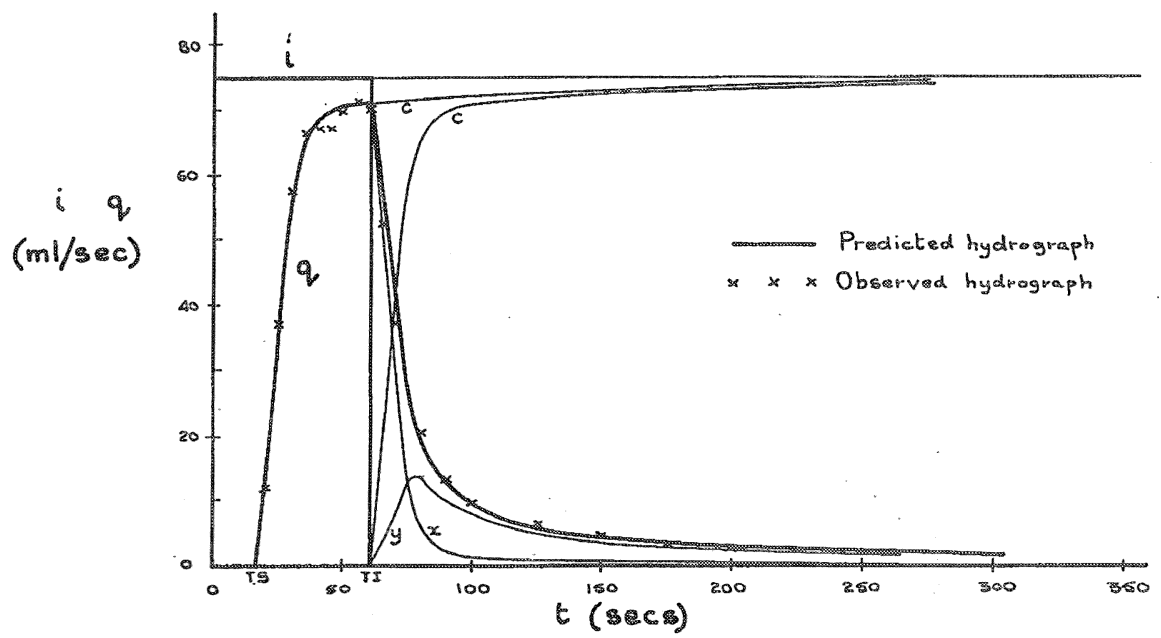

Figure 1.3 Results for a short-duration rain. (Shows TS, c and y).

\subsection{Time-Variant Rainfall}

In practice the intensity of rainfall often varies considerably during the course of a storm. Construction of hydrographs is illustrated in Figure 1.4.

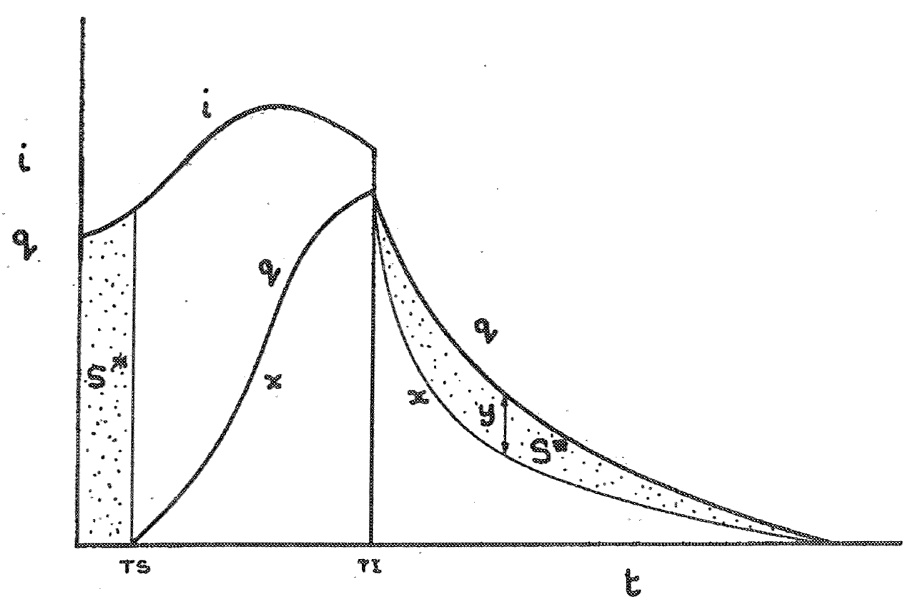

Figure 1.4 Method for a varying rain. 
The mean parameters $\mathrm{S}^{*}, \mathrm{c}_{1}{ }^{*}(\mathrm{t})$ and $\mathrm{y}^{*}(\mathrm{t})$ are known. Equation 1.29 is generalized to:

$$
S=\int_{0}^{T S} i(t) \cdot d t
$$

from which TS is found numerically. An IUH for the linear component is derived using

$$
h(t)=\frac{d}{d t} c_{1}^{*}(t)
$$

where:

$$
h(t)=\text { IUH for the linear component }
$$

The linear component of runoff $x$ is then obtained by convolution of the IUH and the linear component of rainfall (see Equations 1.2 to 1.25 ). The final step is identical to that which has already been given:

$$
q(t)=x(t-T S)+y(t-T I)
$$

It was decided to conduct two tests, and to compare the calculated against observed hydrographs. By using the mean parameters, which had been exhaustively proved whilst working with tests which involved constant intensities of rainfall, it was ensured that any irregularities in the final results could be attributed to the effect of the time-variation in rainfall intensity. The graphical synthesis of the required hydrographs is shown in Figures 1.5 and 1.6. Three stages were involved.

1. In each case TS was found from

$$
\mathrm{TS}=\mathrm{S}^{*} / \mathrm{i}_{1}
$$

where $i_{1}=$ initial rainfall intensity.

2. The linear component of the rainfall graph was split into two pulses. The runoff graphs for each pulse were derived using C-curves, as before.

3. Finally the two linear components and the $y(t)$ curve were added together to form the calculated hydrograph. Both the calculated and the observed hydrographs are shown in part (b) of Figure 1.5 and Figure 1.6.

In both cases the observed and the calculated hydrographs are very similar. This suggests that the theory is applicable when the rainfall intensity varies with time. However, as only two tests were performed, this conclusion is only regarded as provisional. It will be necessary to analyze many more hydrographs, obtained under a wider variety of rainfall conditions, before definite conclusions can be drawn. 

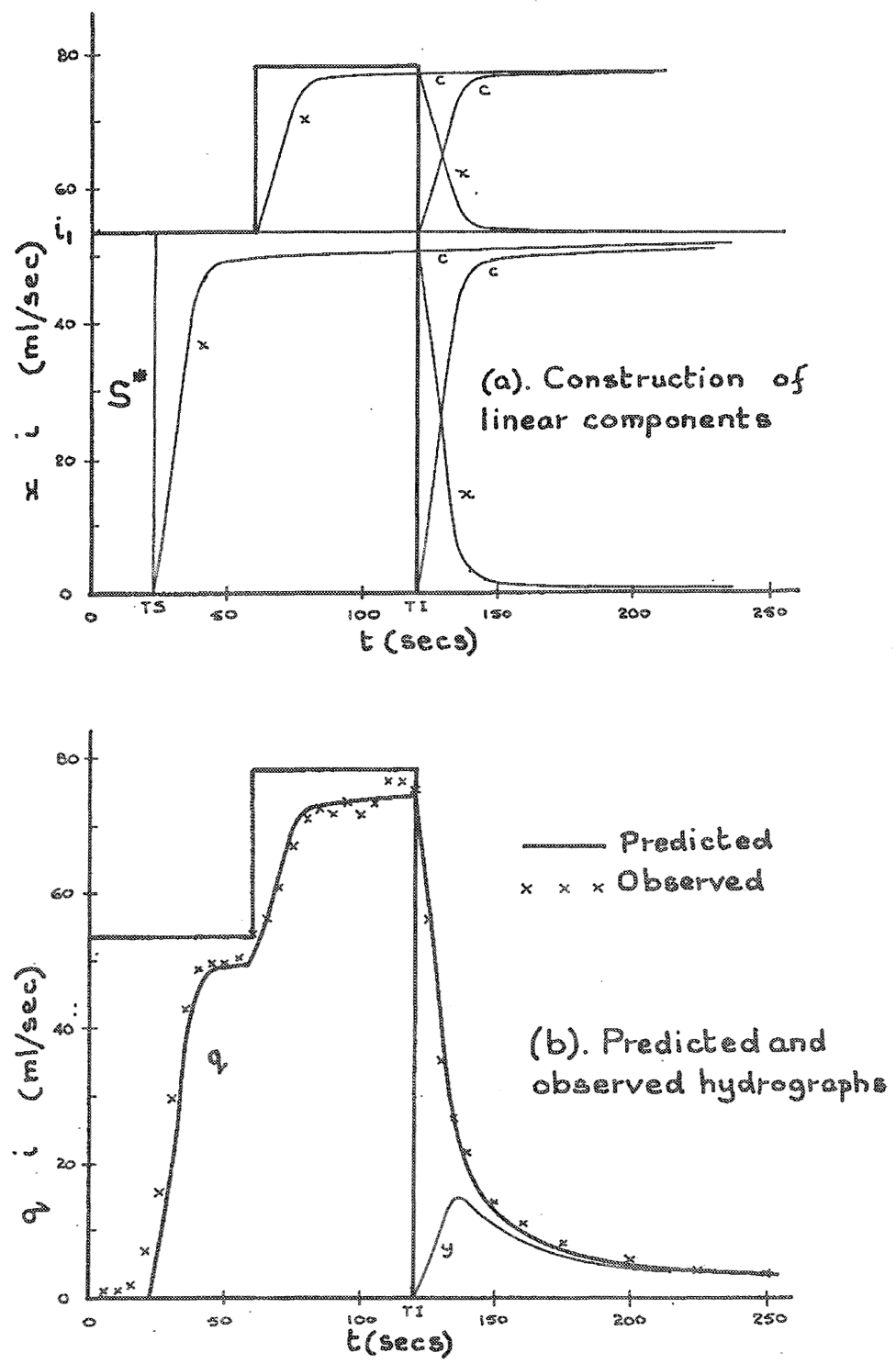

Figure 1.5 Results from a variable increasing rain.

\subsection{Conclusions}

All rainfall-runoff theories embody assumptions which limit their applicability to certain types of surface conditions. Here only the effective rainfall and surface runoff component of the total rainfall-runoff system has been considered. For the 

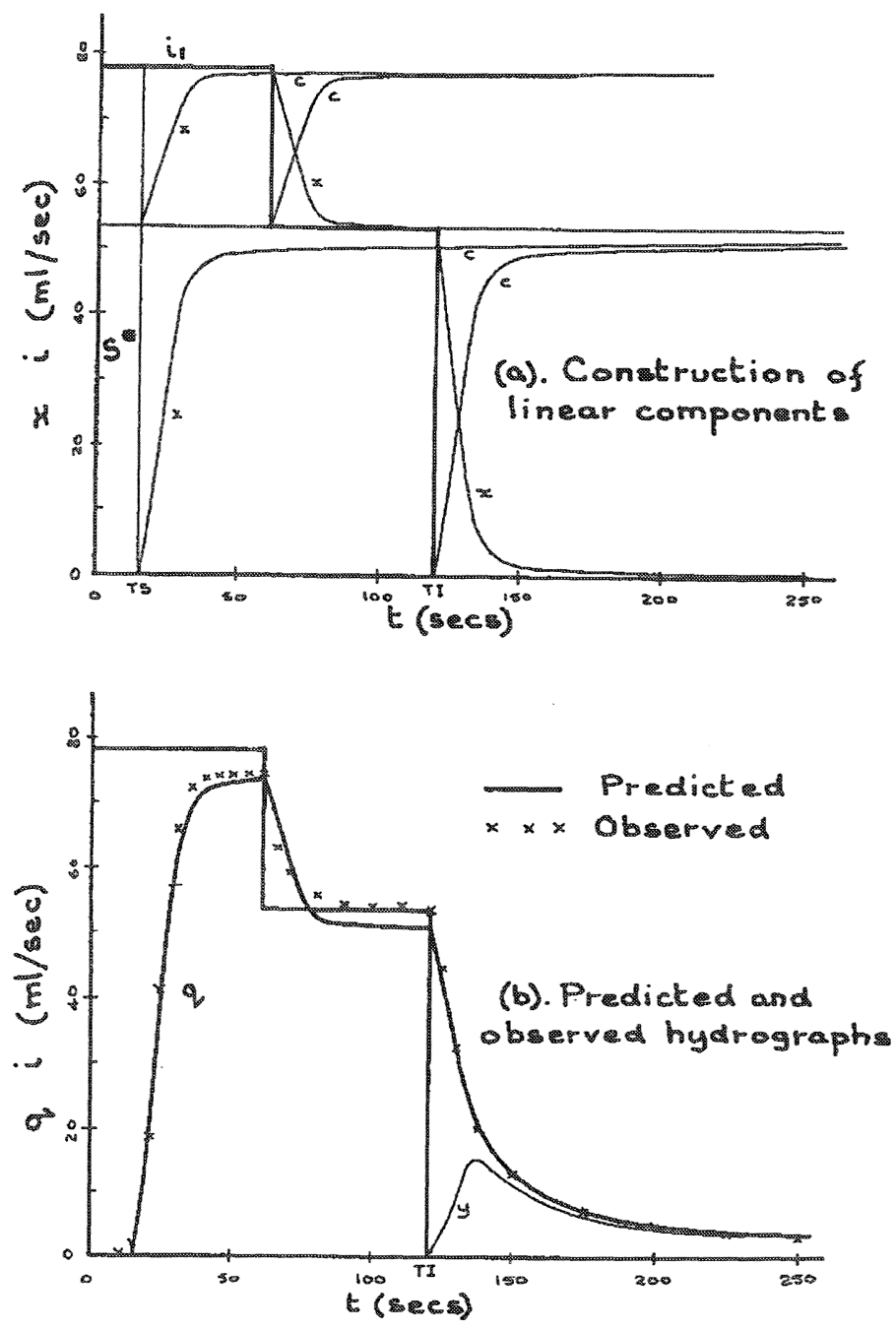

Figure 1.6 Results for a variable decreasing rain.

calculation of floods on pervious surfaces it is also essential to be able to estimate with reasonable accuracy both the quantity and the time distribution of infiltration. This is difficult as the process depends on such factors as the soil type and the history of antecedent precipitation. Clearly, no matter how well any theory may account for the behavior of the surface runoff from a ground surface, its practical usefulness will remain limited until an effective method of dealing with the problem of infiltration is found. 
It was assumed that the characteristics of the ground surface which affect surface runoff do not change with time. This assumption is violated whenever there is a seasonal or a gradual change in the soil cover. Such occurrences are common in reality, and the problem may be partially overcome by approximating the continuous changes to a series of stages, each of which may be considered to be time-invariant.

It is difficult to define a quantitative standard whereby a method may be judged to be successful or not (Amorocho, 1963). A somewhat subjective standard was adopted here: two theories were judged by comparing a calculated to an observed hydrograph. Bearing in mind the accuracy made possible through laboratory controls, it was decided that the ordinates of the two curves should not differ by more than $10 \%$ of the peak value. Where the hydrographs were steep this rule was relaxed, and the effective time lag between the two hydrographs was considered a better index of accuracy.

The duration of the applied rainfall was varied to cover a representative range of conditions. In some cases it was almost as short as the initial storage period whilst in others it was long enough to allow the rate of runoff to approach equilibrium value. Generally speaking, it was impossible to derive accurate IUHs from our experimental data. Two important deductions follow:

1. Our laboratory pavement exhibited highly non-linear characteristics. Investigations were made into the difficulties experienced in the application of linear theory. The assumption of linearity was found to be so erroneous as to necessitate its abandonment.

2. Our method of assessing non-linearity was inadequate. It was intended to monitor any non-linear trends by observing the change in shape of the IUH as the rainfall conditions were varied. The impossibility of deriving satisfactory IUHs precluded this.

In practice linear theory has evidently often been found to yield satisfactory results and it is commonly advocated, e.g. Viessman (1966). In addition, in certain cases it has been found possible to deal with non-linear behavior by using an IUH with a shape which depends on the rainfall conditions. The theories of Minshall (1960), Singh (1964) and Ishihara (1963) are examples. In contrast to linear theory, the IST was shown to be a very workable tool in the analysis of experimental data. A method whereby the theory may be applied to tests in which the rainfall is time-variant was outlined, and two tests were conducted. The accuracy achieved in the calculated hydrographs approached the desired standard. As the results were very encouraging, further testing is warranted.

As opposed to its linear counterpart, IST was especially developed in order to solve a particular problem of the rain-runoff process, viz. the non-linearity in the time dimension. It is interesting to note that although the IST incorporates more assumptions than does linear theory, it is the more flexible method. In the 
special cases (if existing) where the initial storage is zero, the theory reduces to a purely linear one. It was deduced that lumping effectively limits the size of ground-surface response-unit that should be modeled.

\section{Acknowledgments}

This chapter was written shortly after Rob's untimely death. Rob did all the original hard work, and presented it for an MSc degree at the University of Natal. Bill originally provided the research ideas, advisement, facilities and support funds through his research operating grant, and finally wrote the article from Rob's much longer dissertation, as agreed with Rob some months earlier. I have deliberately chosen a gentle title, one that I fancy Rob would have approved. For further information contact Bill at the University of Guelph. An anonymous reviewer of this chapter wished me to add his personal thanks to Rob Johanson for his unheralded inspiration and support during that reviewer's graduate studies.

\section{References}

Amorocho, J. 1963. Measures of the Linearity of Hydrologic Systems. J. Geophys. Research, A.G.U., 68(8):2237-2249 (April. 1963).

Amorocho, J., and Harty W. 1965. The Use of Laboratory Catchments in the Study of Hydrologic Systems. J. Hydrology, 3(1965): 106-123,

Amorocho, J., and Orlob, G.T. 1961. Nonlinear Analysis of Hydrologic Systems. Univ. of California, Water Res. Center Contribution No. 40, Berkeley, California.

Clarke, C.O. 1945. Storage and the Unit Hydrograph. Trans. ASCE, 110:1419-1446 (1945).

Dooge, J.C.I. 1959. A General Theory of the Unit Hydrograph, J, Geophys. Research, A.G.U., 64 (2)s $241-256$

Dooge, J.C.I. 1957. The Rational Method for Estimating Flood-Peaks: Irish Contributions to the Technique. Engineering, 184, (4774, 4776): 311-313, 374-377 (Sept. 6 \& 20, 1957).

Eagleson, P.S., Mejia-R, R., and March, F. 1966. Computation of Optimum Realizable Unit Hydrographs. Water Resources Research, 2(4): 755-764 (1966).

Grace, R.A. and Eagleson, P.S. 1966a. Construction and Use of a Physical Model of the Rainfall-Runoff Process. M.I.T. Hydrodynamics Lab. Technical Note No. 11 (June 1966). Cambridge, Massachusetts. 
Grace, R.A., and Eagleson, P.S. 1966b. The Modeling of Overland Flow. Water Resources Res. 2(3): 393-403

Ishihara, T., and Takasao, T. 1963. Applicability of Unit-Hydrograph Method to Flood Prediction. Proc. 10th Congress I.A.H.R. (London), 2, (1963).

Izzard, C.F. 1946. Hydraulics of Runoff from Developed Surfaces. Proc. Highway Research Board, 26: 129-150

Izzard, C.F. 1944. The Surface Profile of Overland Flow. Trans. Am. Geophys. Union, 25: $959-968$ (1944).

James, W., and Johanson, R.C. A Note on the Non-Deterministic Analysis of Hydrologic Systems. U of Natal, Dept. of Civ. Eng., Report CEPM. 1. (1967), Durban, South Africa.

Johanson, R. C. 1967. System Analysis of the Rainfall Runoff Process, M.Sc. Thesis, U. of Natal.

Linsley, R.K., Kohler, M.A., and Paulhus, L.H. 1949. Applied Hvdrology. New York: McGraw-Hill Inc.

Minshall, N.E. 1960. Predicting Storm Runoff on Small Experimental Watersheds. J. Hyd. ASCE, 86(HY8): $17-38$

Morgali, J.R., and Linsley, R.K. 1965. Computer Analysis of Overland Flow. J. Hyd. Div. ASCE, 91(HY3): 81-100

Nash, J.E. 1957. The Form of the Instantaneous Unit Hydrograph. Proc. General Assembly of Toronto, I.A.S.H., Publication No. 45, Vol. 3, (1957).

Nash, J.E. 1960. A Note on an Investigation into Two Aspects of the Relation between Rainfall and Storm Runoff. I.A.S.H. Commission on Surface Waters, Proc. Gen. Assembly of Helsinki Publication No. 51

O' Donnell, T. 1960. Instantaneous Unit Hydrograph Derivation by Harmonic Analysis. I.A.S.H., Commission on Surface Waters, Publication No. 51: 546-557 (1960).

Sherman, L.K. 1932. Streamflow from Rainfall by the Unit Hydrograph Method. Engineering News Record, 108 (14): $501-505$ (April 7, 1932).

Singh, K. 1964. Non Linear Instantaneous Unit Hydrograph Theory. J, Hyd, Div, ASCE, 90 (HY2): 313-347

Viessman, W. 1966. The Hydrology of Small Impervious Areas. Water Resources Research, 2(3): 405-412

Yu, Y.S., and McNown, J.S. 1964. Runoff from Impervious Surfaces. J. of Hyd. Research, 2(1): 3-24 (1964). 
